\title{
Aldo Castellani y las expediciones de la Royal Society al país del sueño negro
}

Walter Ledermann D.

\begin{abstract}
Socio Honorario Sociedad Chilena de Infectología.

Recibido: 15 de abril de 2011
\end{abstract}

Correspondencia a: Walter Ledermann D. revinf@sochinf.cl

\section{Aldo Castellani and the expeditions of the Royal Society to the black sleep's country}

At the beginning the investigation on infectious diseases was plenty of adventures in exotic countries. The efforts of the English investigators, headed by Patrick Manson, gave birth to the "tropical” medicine and "tropical" diseases, like the sleeping sickness, which was sweeping the country north to the Victoria Lake in 1901. The Royal Society of London sent two Commissions in search of the etiological agent. Aldo Castellani was decisive for the failure of the first - Low, Castellani, Christy,1902 - because even he saw Trypanosoma in samples of some patients, he did not appreciate his discovery; and decisive also for the success of the second -Bruce, Nabarro, Greig, 1903 - when he and Bruce recognized this Trypanosoma as the etiological agent. Following these expeditions, Low developed a brilliant career in England, Christy a life of investigation mixed up with adventures through Asia and Africa and Castellani a long life of lights and shadows in many lands.

Key words: Seeping sickness, Low, Castellani, Christy, Bruce.

Palabras clave: Enfermedad del sueño, Low, Castellani, Christy, Bruce.

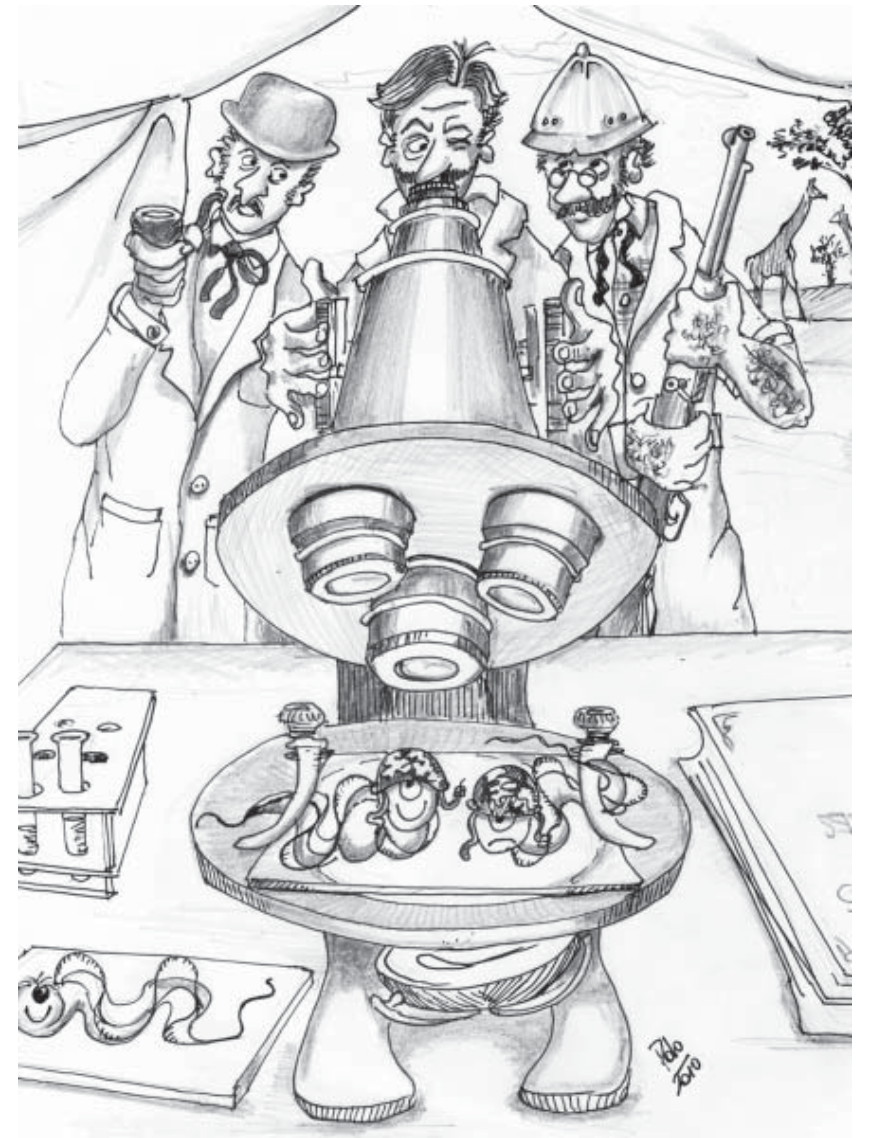

$\mathrm{H}$ acia finales del siglo XIX, el siglo de los grandes descubrimientos en el campo de las enfermedades infecciosas, un verdadero frenesí por lograr el gran hallazgo parecía haberse apoderado de los investigadores, quienes no trepidaban en viajar a países exóticos y peligrosos buscando dilucidar la etiología de alguna supuesta enfermedad infecciosa. África y Asia eran los continentes con mayores oportunidades: ingleses y franceses, que ya los habían invadido y conquistado militar, comercial y políticamente, querían hacerlo también humanitariamente, buscando la causa y la cura de males atroces que los diezmaban, como la malaria, la elefantiasis y otras que sólo tenían nombres nativos, siendo bautizadas por los europeos de acuerdo a sus síntomas, como la "enfermedad del sueño".

Entrando al siglo XX, Inglaterra, con Patrick Manson y sus brillantes discípulos, estaba un paso adelante de otras naciones en el esclarecimiento de las "enfermedades tropicales”, llegando a fundar la Sociedad de Medicina e Higiene Tropical en enero de 1907, a partir de una idea generada en 1899 por James Cantlie. Era una asociación plena de estrellas; en su primera reunión, presidida por el propio Manson, fueron elegidos miembros honorarios Robert Koch, Paul Ehrlich, Alphonse Laveran, Teobald Smith, Camilo Golgi, Ettore Marchiafava, Carlos Finlay, Shibamiro Kitasato, K. Shiga... ${ }^{1}$. El impulso que esta sociedad daría a la investigación sería inmenso, pero fue la Real Sociedad de Londres (The Royal Society of London 
for Improving Natural Knowledge), fundada en 1660, la que montó las expediciones en busca de la etiología de la “enfermedad del sueño”o "letargo negro".

Se llamaba así a esta patología porque, siendo propia de Árica, afectaba a los hombres de raza negra, sus habitantes naturales, y porque los afectados caían en un letargo o “sueño" previo al coma y a la muerte. Sabemos hoy que es una encefalitis causada por un tripanosoma, transmitida por un mosquito y, por lo tanto, susceptible de prevenir y erradicar; que existen medicamentos profilácticos y terapéuticos, pese a lo cual y desgraciadamente, es "frecuentemente fatal"2.

Aunque no lideró ninguna de las expediciones, el papel de Aldo Castellani sería decisivo, tanto para el fracaso de la primera como para el éxito de la segunda. Nacido en Florencia el 8 de septiembre de 1874, en el seno de una antigua familia de productores de vino Chianti, se graduó de médico magna cum laude el 7 de julio de 1899 en la Universidad de Florencia, con una tesis sobre el aislamiento del "bacilo tifoso" en hemocultivos, pese a que se sentía atraído por la dermatología. Era hombre muy culto y brillante, que hablaba fluidamente varias lenguas, hábil en la argumentación, gran narrador de historias. Siempre quiso compartir la clínica con la investigación; era famoso entre sus compañeros por la intensidad con que examinaba y percutía a sus pacientes, otorgándole el apodo de Martellino (pequeño martillo). Tras una estadía de tres años en el Instituto de Higiene de Bonn aprendiendo microbiología con el profesor Walter Krusse, fue aceptado para trabajar con Manson en Londres. Desde niño había, en sus propias palabras, "sentido la urgencia de viajar a los trópicos y trabajar allí”, y cuando surgió la oportunidad de participar en la primera expedición se ganó un lugar superando a otros treinta postulantes, gracias a una recomendación de Manson al Foreign Office ${ }^{3,4}$.

\section{La primera expedición:}

George Low, Aldo Castellani y

Cuthbert Christy, 1902

En la ribera norte del lago Victoria, en la nación que hoy es Uganda, en 1902 una epidemia había causado unas veinte mil muertes, ante lo cual la Real Sociedad de Londres no pudo permanecer indiferente y decidió enviar a terreno una "Comisión para la Enfermedad del Sueño", como lo anunciaba The New York Times en su edición del 22 de junio de 1902:

20,000 Persons Die from “Sleeping Sickness” . Mission for Study the Fatal Disease in Uganda Sent Out by the British Foreign Office and the Royal Society.

En el texto se decía que los últimos informes de Uganda indicaban que sólo en Busoga habían sucumbido 20.000 personas y que estaría aumentando. La expedición consistía en el Dr. Low, quien había retornado de investigar la fiebre amarilla en Santa Lucía y recientemente llevado a cabo interesantes experimentos en relación a la malaria en Campagna Romana; del Dr. Christy, quien había realizado valioso trabajo médico en Níger y en conexión con la peste en India, y el Dr. Castellani "del Instituto Jenner" (?). Estos caballeros, continuaba el artículo, irán directo de Marsella a Entebbe, sus cuarteles en Uganda, vía Mombasa (recordemos que el canal de Suez estaba abierto desde 1869). Agregaba que el costo del transporte y mantención de los miembros de la expedición era financiado por el Gobierno Británico, más un grant de 600 libras esterlinas de la Real Sociedad para equipos y pago de los doctores ${ }^{5}$. Inmediatamente a continuación, como un subtítulo de la noticia, encontramos “Un ciclista corre con un león”; creímos que en Uganda, pero era en la civilizada Suiza: un león escapó desde el tren donde era transportado y persiguió por la carretera al señor Spring, quien pedaleó vigorosamente y sacó buena ventaja a la fiera, abatida a tiros por el manager de la Ménagerie Ehlbeck.

Recientemente Douglas Haynes ha retomado la acusación contra Patrick Manson de haber forzado la expedición por intereses personales, usando todo su poder y su influencia en la Real Sociedad, exagerando la posible diseminación de la epidemia de Uganda, públicamente en la prensa y privadamente en el Foreign Office. ¿Cuáles serían esos intereses? Años antes, en 1891, Manson había encontrado en Londres Filaria perstans en dos casos de "letargo negro" y quería confirmar esta posible etiología sin salir de casa, de manera que se movió incansablemente hasta lograr que la expedición se hiciera: irónicamente, dice Haynes, para desaprobar su hipótesis ${ }^{6}$.

Embarcaron en Marsella los tres brillantes investigadores: el casting de esta película de aventuras parece haberlo hecho alguien con un peculiar sentido del humor, pues eran personalidades tan singulares, tan distintas entre sí, que era posible desde el comienzo pronosticar un conflicto. Low, de 29 años, era un caballero inglés, un investigador serio y honesto, de gran juicio crítico; Castellani, de 24 años, ya presentado, hombre múltiple y genial ; y el escocés Christy, de 38 años, por encima de todo un cazador y hombre de acción.

George Carmichael Low (1872-1952) trabajaba desde 1899 con Patrick Manson en la recién fundada Escuela de Medicina Tropical de Londres y acababa de terminar una valiosa investigación en el Caribe, destinada a una mejor comprensión de la filariasis. De paso, el joven Low contribuyó a la lucha contra la malaria, al enfrentar un brote de una grave enfermedad ictérica en la isla de Santa Lucía, para la cual se postulaban los diagnósticos de malaria y de fiebre amarilla. Pese a su escasa experiencia, Low demostró la coexistencia de ambas enfermedades y propuso sabias medidas de control ${ }^{7}$. Low tenía la costum- 
bre de informar de todos sus pasos a su respetado maestro Manson, escribiéndole largas y numerosas cartas; tanto éstas como las que le escribió durante la expedición que vamos a relatar, constituyen un verdadero tesoro para los historiadores.

Cuthbert Christy (1863-1932), médico graduado en Edimburgo, ha sido definido como explorador, zoólogo y cazador. Al momento de la expedición era, con sus 39 años, el más "viejo" de los tres integrantes y, por ende, el más experimentado. Ya había viajado a Sudamérica y a las Indias Orientales, había sido oficial médico británico en Nigeria, trabajado en India con Haffkine en Bombay y luego desempeñado como cirujano civil en Ahmendnuggar y Satara. En 1899 pasó un par de meses en Surat, inoculando a los pobladores con un suero antipestoso fabricado por Haffkine, plasmando todas sus experiencias indias en un valioso documento, el Álbum de India, que comprende sus diarios y fotografías ${ }^{8}$. También había publicado el primero de sus varios libros, sobre los mosquitos de la malaria9.

Cuando la nave arribó a Mombasa ya habían peleado -y varias veces- Christy con Low. Podemos suponer que Christy, diez años mayor y más experimentado, no soportara de buen grado verse bajo la jefatura del bisoño Low, y podemos imaginar al napolitano Castellani tratando de limar las asperezas con alguna broma. Lo cierto es que las relaciones no mejoraron durante el viaje en tren a Entebbe, y que Christy terminó por distanciarse, dedicando la mayor parte de su tiempo a la exploración y la caza, sin que por ello haya descuidado su misión de estudiar la ecología de la epidemia, puesto que publicó a su regreso un excelente y breve informe, apenas cinco páginas, que sirvió para descartar la existencia de Filaria perstans en la zona ${ }^{10}$

La expedición fracasó, puesto que no encontró al agente etiológico, o, peor aún, porque lo encontró y lo desechó. ¿Cómo pudo ocurrir tamaño desaguisado, contando la expedición con dos talentos como Low y Castellani? Creemos que hubo culpas compartidas, entre los dos citados y el mismísimo Manson. Éste habría encargado específicamente a su discípulo buscar la filaria: la mucha devoción por el maestro parece haber cegado a Low, impidiéndole valorizar adecuadamente los hallazgos del Castellani. Y éste, destacado en la expedición como bacteriólogo, fue en busca de una bacteria y se ofuscó en su búsqueda a causa de una curiosa información que Manson enviara a Low. En una de sus cartas le habría hablado de -o trascrito o adjuntado- un informe portugués acerca de una bacteria, específicamente un estreptococo, como etiología de la enfermedad del sueño ${ }^{11}$.

Quién pudo ser ese investigador portugués y dónde publicó su hallazgo, si llegó a publicarlo, es un misterio, pero Castellani se aferró a él, deslumbrado, y terminó por ver organismos similares a estreptococos, en casi todos los casos que estudiara, pese a que vio un tripanosoma en una muestra de líquido cefalorraquídeo (LCR), y lo dibujó con pelos (o flagelos...) y señales. Pero no le dio importancia y siguió postulando la candidatura de su bacteria, que informó finalmente como diplococo. La Comisión de Malaria (¿’) de la Real Sociedad dijo que esta conclusión de Castellani era prematura y se necesitaban further studies ${ }^{12}$.

Uno llega a preguntarse si tal informe portugués existió. Si no fue así... ¿ por qué Manson transmitiría a los expedicionarios un rumor no confirmado, que echaba por el suelo su Filaria perstans ? ¿ Y por qué Castellani desechó el hallazgo del Trypanosoma, cuando lo tuvo bajo sus ojos en el microscopio? Y, ya que de un portugués se trata, podemos imaginar al Trypanosoma brucei gambiense, atrapado entre los dos vidrios de la preparación, recitándole desde la platina al napolitano estos versos (cambiando “amor” por “alcohol”) de los "Sonetos del portugués”, de Elizabeth Browning ${ }^{13}$.

\section{Tú puedes contemplarme sin zozobras como una abeja en urna de cristal... Reclusa del dolor en alcohol puro abrir las alas para alzar el vuelo por el aire exterior fuera imposible.}

Para volar en el "aire exterior”, el Trypanosoma brucei gambiense necesitaba la ayuda de la mosca tsé-tsé, la Glossina palpalis; para llegar a descubrir esta verdad se necesitaría una Segunda Comisión. La primera había terminado sin brillo; Castellani continuó investigando en Entebbe, mientras Low y Christy se separaron cuanto antes, el primero para seguir una carrera de moderados éxitos en Londres y el segundo para continuar sus aventuras por los trópicos.

Low asumió la superintendencia de la Escuela de Medicina Tropical, desempeñándose al mismo tiempo como patólogo en el Hospital Oeste; luego pasó al Hospital de Enfermedades Tropicales y finalmente fue director de la División de Clínica de Medicina Tropical en la famosa Escuela, donde haría una fructífera carrera con más de 250 publicaciones, siendo las más importantes las de filariasis. Su pasión, sin embargo, era la ornitología, ciencia en que destacó. Gordon Cook, el gran historiador de la medicina tropical, se ha preguntado por qué tan poco se sabe de Low, por qué no obtuvo distinciones civiles y si ello se debe a que fue disminuido por la figura Manson, entonces y ahora ${ }^{14}$. Creemos, humildemente, que entre los gigantes de entonces, como Manson, Ross o Bruce, Low fue una figura distinguida, pero menor.

Aunque Christy esperó a la segunda Comisión, no se incorporó a ella, continuando su vida médica y aventurera en Congo, desde donde viajó a Ceilán (hoy Sri Lanka), volvió al este de África, de nuevo a Uganda, Nigeria, 
Costa de Oro y Camerún. En la Primera Guerra Mundial fue destacado en África y Mesopotamia; después exploró Sudan, Nyasaland, Tanganyika, para concluir como miembro de una comisión de la Liga de Naciones para investigar la esclavitud en Liberia . A continuación de su primer libro sobre la malaria, publicó varios más, sobre sus exploraciones, la industria del caucho, los pigmeos y la caza mayor ${ }^{15}$. Murió en su ley, cazando en Congo, embestido por un búfalo, “la bestia más cobarde, sanguinaria y carnicera, la más empecinada en su ataque, la de instintos más crueles... se mantiene inmóvil en la sombra de la arboleda hasta que de pronto, cuando se han acortado las distancias, inicia una carga inesperada y rápida... de un búfalo solitario hay que cuidarse siempre: viejo o enfermo, busca venganza"16. En el obituario en Nature se cuenta que participaba de un trabajo científico para el gobierno belga y que mientras cazaba en la región del río Aka, murió corneado por un búfalo ${ }^{17}$. Por otro obituario, publicado por la Real Sociedad Africana, nos enteramos de los detalles: era un verdadero safari en busca de elefantes, con Christy, tres cazadores nativos, dos boys y veinticinco portadores; el 27 de mayo nuestro héroe avistó búfalos y "abriendo fuego a un rango de sesenta yardas, hirió a un macho que de inmediato cargó y lo corneó. El búfalo fue muerto por un cazador nativo, el Dr. Christy retirado del campo y un corredor enviado al puesto más cercano en busca de ayuda. El Dr. Christy, sin embargo, se puso peor y murió antes que la ayuda llegara. Su cuerpo fue llevado a la base, donde, envuelto en una Union Jack, fue quemado en presencia de oficiales y otros" ${ }^{\prime 18}$.

\section{La segunda expedición: \\ David Bruce, David Nabarro y \\ Edward David Greig, 1903}

Esta segunda expedición fue más modesta y silenciosa, pero bastante más productiva. Por una parte, en la espera Castellani había recapacitado, dudado de su estreptoco pneumococcus-like y encontrado ya cinco tripanosomas sobre 15 muestras de LCR; y, por otra, Bruce llegaba con un tremendo historial de exitosa investigación, que incluía el descubrimiento del agente causal de la brucelosis, así como su mecanismo de transmisión; y, más importante aún para la investigación en curso, había elucidado la causa y la patología del nagana, enfermedad del sueño del ganado, cuyo agente etiológico identificara como un "hematozoa" (más tarde Trypanosoma brucii o brucei) y su vector como la mosca tsé-tsé Glossina palpalis ${ }^{19}$. No haremos mayor presentación de este investigador, del cual nos hemos ocupado en otra oportunidad, con motivo de la enfermedad de Malta $^{20}$, salvo agregar que compartía las aficiones de su compatriota Christy por las aventura, la exploración y la caza mayor: es clásica su foto de la
Wellcome Library, London, donde lo vemos sentado sobre una piel de leopardo en el porche de su casa en Ubombo, rifle en mano, canana llena de municiones a la cintura, sombrero de Indiana Jones, teniendo como fondo el pasillo repleto de cornamentas .

Edgard David (todos se llamaban David) Wilson Greig (1874-1950) era también escocés, como Bruce, graduado de médico en Edimburgo. Tras ejercer breve tiempo en Londres, en 1899 había ingresado al Servicio Médico de India y, por su interés en la investigación de la peste bubónica, fue seleccionado para unirse a la Segunda Comisión para la enfermedad del sueño. Ya había ganado tres premios: el Herbert Memorial al mejor estudiante del año en el Army Medical Collage, el Fryer Prize en Medicina Tropical y el Premio Montefiore en cirugía. Bastante, para un investigador de apenas 29 años ${ }^{21}$.

En cuanto a David Nunes Nabarro (1874-1958), poco hemos encontrado: era portugués, pero no el misterioso del estreptococo que cegara a Castellani. Se le menciona como patólogo y se le describe como "un portugués tranquilo" y "un investigador muy entrenado"22; veremos más adelante que se mostraría, además, honesto y cabal al reconocer los méritos de Castellani.

Cuando Bruce llegó a Entebbe, ya Castellani había encontrado en cinco de quince pacientes un tripanosoma en muestras de LCR, y también en la sangre de uno de ellos. Bruce vio de inmediato la importancia del hallazgo y profundizó metódicamente el estudio en esta línea, encontrando el tripanosoma en $70 \%$ de los LCR de 34 enfermos y en ninguno de 12 controles sanos, subiendo el porcentaje a $100 \%$ en una nueva serie de 40 pacientes. Para cumplir con los postulados de Koch inoculó un mono con LCR de un enfermo: el mono hizo un símil de enfermedad del sueño, pero el resultado no fue válido, porque en su autopsia se encontró co-existencia de tuberculosis. Entonces se dedicó a inocular animales subcutáneamente con sangre de enfermos, encontrando en las autopsias de los susceptibles los tripanosomas en el sistema nervioso central. Simios, perros y las ratas eran parcialmente susceptibles a la enfermedad, no así los cobayos, cabras, ovejas y burros. La etiología de la enfermedad del sueño estaba descubierta ${ }^{23}$.

Sin embargo, Aldo Castellani había, con toda justicia y derecho, publicado antes. Ello desataría una ácida controversia, primero privada y luego pública, en los periódicos, cuyas razones intentaremos narrar ordenadamente. Bruce y Nabarro llegaron en marzo de 1903 a Entebbe, donde los esperaba Castellani. Todavía dudoso entre sus estreptococos y sus tripanosomas, el investigador florentino temía ser ridiculizado por Bruce y, más aún, por Nabarro, cuya supervisión no le agradaba, y por ello mostró condicionalmente sus preparaciones al escocés. Fueron sus condiciones seguir buscando tripanosomas, para confirmar su teoría etiológica, y publicar su hallazgo 
como primer y solitario autor. Bruce habría aceptado, pero pidiéndole que no se precipitara y no publicara hasta estar seguro, de modo que en las tres semanas siguientes Castellani encontró tripanosomas en otros veinte casos, adiestró a Bruce en punciones lumbares y en el examen microscópico de LCR: recordemos que era un bacteriólogo experto, discípulo de Krusse ${ }^{24}$.

$\mathrm{Al}$ parecer, cumplidas estas tres semanas y viendo a Bruce lanzado en pos del tripanosoma, desconfió y temió que éste, más célebre y de mayor crédito, se le anticipara, de modo que volvió rapidito a Londres y envió su descubrimiento el 5 de abril de 1903, como report number one de la Comisión ${ }^{25}$, publicándolo luego en los Proceedings de la Real Sociedad ${ }^{26}$. Bruce, nada feliz con la publicación, descalificó al florentino en el report number four, firmado por Bruce, Nabarro y Greig²7, diciendo que "para ayuda un futuro historiador, cuando llegó la Comisión el Dr. Castellani no consideraba que el tripanosoma tuviera alguna relación causal con la enfermedad, pensando que era un concomitante accidental, como la filaria”. Explicaba que si él no hubiera valorizado el hallazgo e incentivado al florentino a seguir con sus observaciones, no se habría llegado a descubrir la etiología de la enfermedad. Dicho esto, publicó el descubrimiento como propio ${ }^{28}$.

El prestigio y el peso de Bruce como investigador experto fueron decisivos, y aunque Castellani protestó, llegando la controversia a los periódicos, el tripanosoma llevaría el nombre de Bruce. Nabarro, arrepentido del efecto que había causado este reporte número cuatro, diría cinco años después, en el Times del 3 de julio de 1908: “Al Dr. Castellani debe darse el crédito de haber sido el primero en encontrar el tripanosoma en el fluido cerebroespinal de las víctimas de la enfermedad del sueño, y de haber publicado que la enfermedad del sueño es una infección tripanosómica”. Y, más tarde, reafirmó que siempre, como asunto “de mera justicia”, había dado el crédito a Castellani de haber descubierto primero el tripanosoma, relacionándolo como agente causal de la enfermedad ${ }^{29}$.

Bruce volvió a Uganda durante 1908-1910, renovando o continuando la Comisión, para estudiar exitosamente la transmisión del Trypanosoma (brucei) gambiense por la mosca Glossina palpalis, y estudiar como posibles reservorios el ganado vacuno y el gamo. En 1911, como Director de una nueva Comisión de la Real Sociedad para la Enfermedad del Sueño (parece que ya vamos en la cuarta) a Nyasaland, demostró que allí la mosca Glossina morsitans transmitía el Trypanosoma rhodesiense, para concluir finalmente que ambos tripanosomas y ambas moscas causaban variantes geográficas de una misma enfermedad: hoy en día se va más lejos y se acepta un solo tripanosoma, Trypanosoma brucei, con las subespecies gambiense y rhodesiense.

Castellani se quedó sin tripanosoma, pero continuó una exitosa carrera y una larga vida, falleciendo a los 97 años, tras dejar su nombre ligado a un test de aglutinación, hoy en desuso ${ }^{30}$; a una enfermedad bronquial por espiroquetas $^{31}$; a un síndrome de hepato-esplenomegalia febril con artritis ${ }^{32}$; a un colorante usando en el tratamiento de micosis $^{33}$ y a un famoso Manual de Medicina Tropical, escrito con Albert John Chalmers ${ }^{34}$, con quien comparte también la descripción oficial de varias bacterias. Descubrió el Treponema partenue, causante de la frambesia, siendo pionero en tratarla con salvarsan ${ }^{35}$. Pero sus ideas políticas conspiraban en su contra: siendo un furioso monárquico, adhirió a la causa de Mussolini, de quien era ferviente admirador, participando en la funesta guerra de Italia con Abisinia; il Duce lo hizo Conde de Chisimaio y el Rey Humberto II, para no ser menos, lo hizo Marqués. Terminada la Segunda Guerra Mundial, en 1945 perdió su cátedra en Roma, acusado de fascista, y se fue a Portugal, donde atendió a la familia real italiana en exilio y se desempeñó como Profesor de Patología y Medicina Tropical en el Instituto de Enfermedades Tropicales de Lisboa, ciudad en que falleció a los 97 años, el 3 de octubre de 1971. Bastante arribista, se gloriaba de codearse con la aristocracia y la realeza; su orgullo creció al recibir de Francia la Legión de Honor y ser nombrado Caballero por la corona británica, título que se le retiró por fascista durante la guerra y se le restituyó poco antes de morir ${ }^{36}$. Cuánto valoraba sus relaciones con las testas coronadas se desprende del título de sus memorias: "Microbios, hombres y monarcas -una vida de doctor en muchas tierras”37, donde iguala a los reyes con las bacterias, que son mucho más importantes y productivas.

En cuanto a la epidemia en Uganda, duraría veinte años, causando más de 250.000 muertes $^{38}$.

\section{Resumen}

En un comienzo la investigación sobre enfermedades infecciosas estuvo llena de aventuras en países exóticos. Impulsada por los investigadores ingleses, encabezados por Patrick Manson, nacieron la medicina y las enfermedades "tropicales", entre las cuales se encontraba la enfermedad del sueño, que a comienzos del siglo XX hacía estragos al norte del lago Victoria. La Real Sociedad de Londres envió dos Comisiones a Uganda para determinar el agente etiológico. Aldo Castellani fue decisivo para el fracaso de la primera, que incluía también a Low y Christy, en 1902, pues aunque vio tripanosomas en LCR de enfermos, no les otorgó valor y prefirió postular un diplococo como agente causal; y decisivo también para el éxito de la segunda, de Bruce, Nabarro y Greig, en 1903, al concordar con Bruce en que el tripanosoma era realmente el causante de la enfermedad. Después de estas expediciones, Low desarrolló una brillante carrera en 
Inglaterra, Christy una vida que combinaba investigación con aventura en Asia y África, y Castellani una larga vida de éxitos, oscurecida por sus ideas políticas, que lo ligaban a Mussolini.

\section{Referencias}

1.- Cook G C. Tropical Medicine. An illustrated history of the pioneers. 7. James Cantlie (1851-1926): tropical surgeon, university administrator, and founder of the (Royal) Society of Tropical Medicine and Hygiene. Academic Press, London 2007; pp. 115-26.

2.- Tripanosomiasis Africana. El Manual Merck de Diagnóstico y Tratamiento. Edición del centenario. 10 $10^{a}$ edición española, Harcourt España s.A., Madrid 2008; pp. 1255-6.

3.- Binazzi M. Italian memoirs of Aldo Castellani. Int J Dermatol 1991; 30 (10): 741-9.

4.- Ransford O N. Sir Aldo Castellani - an international man. Practitioner 1980; 224 (1346): 861-3.

5.- 20,000 Persons Die from "Sleeping Sickness". The New York Times, June 22, 1902.

6.- Haynes D M. Framing tropical disease in London : Patrick Manson, Filaria perstans, and the Uganda sleeping sickness epidemic, 1891-1902. OAH Soc Hist Med 2000; 13 (3): 467-93.

7.- Bramwell Cook H. Gordon Cook's Caribbean diseases: Doctor George Low's expedition in 1901-02. Radcliffe Publishing 2009. The New Zealand Medical Journal 2010; 123: 1320.

8.- Cuthbert Christy Album of India 1899-1901. Access and use: Cambridge University Library; Royal Commonwealth Society Library, Y3022V.

9.- Christy C. Mosquitoes and malaria. African Hunter Traveller Books. http://www.shakariconnection.com

10.- Christy C. The distribution of sleeping sickness, filarial persistans, in East Africa. Rep II ( $\left.{ }^{\circ} 3\right)$ Harrison and Sons, London 1903; pp. 3-8.

11.- Cook G. Tropical Medicine. An illustrated history of the pioneers. Academic Press, London 2007; pp. 133-5.

12.- Ito, K. Aldo Castellani, 1874-1791. Bull NY Acad Med 1984; 60 (10): 1011-29.

13.- Browning E B. Sonetos del portugués y otros poemas. Introducción y traducción en verso de Carlos Pujol. Editorial Planeta S.A. Barcelona 1989; soneto XV, p. 67.

14.- Cook G C. George Carmichael Low FRCP: twelfth President of the Society and underrated pioneer of tropical medicine. Trans Royal Soc Trop Med Hyg 1993; 87 (4): 355-60.

15.- Cuthbert Christy's books. African Hunter Traveller Books. http://www.shakariconnection.com

16.- Barros Prado E. El último safari. Ediciones Peuser, Buenos Aires 1963; pp. 300-2.

17.- Anonymous. Obituary. Dr. Cuthbert Christy. Nature 1932; 180: 85.
18.- Anonymous. Obituary. Dr. Cuthbert Christy. J Royal Africa Soc 1932; 31 (124): 339-42.

19.- Cook, G. Sir David Bruce's elucidation of the aetiology of nagana-exactly one hundred years ago. Trans R Soc Med Med Hyg 1994; 88: 257-8.

20.- Ledermann W. Brucella melitensis, una historia de amor. En: Una historia personal de las bacterias. RIL Editores, Santiago 2007; pp. 209-14.

21.- Anonymous. The Services. Deaths in Services. Br Med J 1950 (May 20); p. 1213.

22.- De Kruif P. Bruce. En: Los cazadores de microbios. Ediciones Occidente S.A. Santiago 1989; p.164.

23.- Bruce D, Nabarro D, Greig E D W. The etiology of sleeping sickness. Br Med J 1903; 2: 1343-50.

24.- Dolman, C.E. Bruce, D. Complete Dictionary of Scientific Biography. Charles Scribner's Sons 2008. Encyclpedia.com 13 Apr 2011 http://www.encyclopedia.com

25.- Castellani A. Presence of Trypanosoma in sleeping sickness. Reports of the Sleeping Sickness Commission of the Royal Society 1903; 1: 3-10.

26.- Castellani A. On the discovery of a species of trypanosome in the cerebro-spinal fluid of cases of sleeping sickness. Proc Royal Soc London 1903; 71: 501-8.

27.- Bruce D, Nabarro D, Greig E D W. Further report on sleepig sickness in Uganda. Reports of the Sleeping Sickness Commission of the Royal Society 1903; 4: 2-88.

28.- Bruce D, Nabarro D, Greig E D W. The etiology of sleeping sickness. Br Med J 1903; 2: 1343-50.

29.- Ito K. Aldo Castellani, 1874-1791. Bull NY Acad Med 1984 (Dec); 60 (10) : 1011-29.

30.- Castellani A. Die agglutination bei gemischter Infektion und die diagnose der letzeren. Zeitschrift für Hygiene und Infektionskrankheiten Leipzig 1902; 40: 1-19.

31.- Castellani A. Note on a peculiar form of haemoptysis with presence of numerous spirochaetae in the expectoration. Lancet 1906; I: 1384-5.

32.- Castellani A. Note on a peculiar febril hepatosplenomegaly with artritis. J Trop Med Hyg London 1935; 38: 229-30.

33.- Seliger H P, Seefried L. Aldo Castellani -an appraisal of his life and oeuvre. Mycoses 1989; 32 (8): 391-7.

34.- Castellani A, Chalmers A J. Manual of Tropical Medicine. Ballière, Tindall \& Cox, London 1910.

35.- Castellani A. On a the presence of spirochaetes in two cases of ulcerated parangi (yaws). Br Med J 1905; 2 (1280): 1330-1.

36.- Cook G C. A difficult metamorphosis: the incorporation of the Ross Institute \& Hospital for Tropical Diseases into the London School of Hygiene and Tropical Medicine. Medical History 2001; 45: 483-506.

37.- Castellani A. Microbes, men and monarchs: a doctor's life in many lands. Gallancz, London 1960.

38.- Fèvre E M, Coleman P G, Welburn S C, Maudlin I. Reanalyzing the 1900-1920 sleeping sickness epidemic in Uganda. Emerg Infect Dis 2004; 10 (4): 567-73. 